\title{
Role of tumour necrosis factor (TNF) in host defence against tuberculosis: implications for immunotherapies targeting TNF
}

\section{S Ehlers}

Studies in mouse infection models clearly demonstrate tumour necrosis factor (TNF) to be a critical component of both the antibacterially protective and the inflammatory immune response to Mycobacterium tuberculosis. It is therefore not surprising that treatment of patients-for example, those with rheumatoid arthritis - with biological agents interfering with TNF activity have shown an increased risk of reactivating tuberculosis. However, conceivably, TNF targeting biological agents can be developed that because of their particular mode of action and their specific pharmacodynamics may be less likely to have this side effect.

B iological therapeutic agents neutralising tumour necrosis factor (TNF) activity are highly successful in treating chronic inflammatory processes, such as Crohn's disease, rheumatoid arthritis, ankylosing spondylitis, uveitis, and psoriasis. ${ }^{1-7}$ In rheumatoid arthritis, in particular, a number of reports have highlighted the dramatic and fast improvement of patient quality of life, and the long term beneficial effects for cartilage and bone preservation that these treatments may afford are currently being evaluated.$^{8-11}$

However, from the beginning (that is, during phase III trials and during immediate post-marketing surveillance), side effects of TNF neutralisation-mostly infectious complications-were clear. ${ }^{12}$ The most important were pulmonary infections-notably, tuberculosis (TB), where the disease in some instances caused death. ${ }^{13}$ This report summarises current knowledge of the role of TNF in both antibacterial protection and the inflammatory response to $M$ tuberculosis infection, as it has been determined from the mouse model of experimental TB. An attempt will then be made $(a)$ to define the properties of TNF targeting biological agents that might reduce infectious complications; and $(b)$ to highlight some pertinent pharmacological features of infliximab and etanercept, the two currently most widely used TNF blockers.

\section{ROLE OF TNF AND LYMPHOTOXINS IN THE MOUSE MODEL OF M TUBERCULOSIS INFECTION}

TNF is a cytokine produced primarily by macrophages in response to stimuli activating toll-like receptors, but can also be expressed by activated T cells, B cells, and NK cells. ${ }^{14}$ TNF occurs as a trimer, both as a soluble and as a transmembrane factor. Both the homotrimeric receptors TNFRp55 and TNFRp75 are involved in binding and signal transduction to both soluble and transmembrane TNF. However, soluble TNF preferentially binds to TNFRp55, whereas the membrane associated form mostly binds to TNFRp75. ${ }^{15}$ The functional consequences of TNFRp55 triggering by far outweigh those initiated by binding to the TNFRp75.

TNF is a multipotent cytokine which plays a part in apoptosis, cell activation, cell recruitment and differentiation. ${ }^{14}{ }^{16}$ The pleiotropic effects of TNF have been elucidated in a number of experimental systems. ${ }^{15}{ }^{17}$ Table 1 summarises the results obtained in intravenous and aerogenic infections with several mycobacterial species in mice.

An effective host response against TB involves the differentiation of specific T cells to secrete an appropriate Thl cytokine profile and the development of granulomas in which activated epithelioid macrophages restrict mycobacterial growth (fig l). TNF is necessary for optimal coordination of both aspects of

Abbreviations: HVEM, herpesvirus entry mediator; KO, knockout; LT, lymphotoxin; TNF, tumour necrosis factor

Table 1 Effects of blocking TNF or LT during experimental mycobacterial infections in mice

\begin{tabular}{|c|c|c|c|c|}
\hline Mycobacterial strain & Experimental system & $\begin{array}{l}\text { Effect on antibacterial } \\
\text { protection }\end{array}$ & Effect on granuloma development & Reference \\
\hline$M$ tuberculosis & TNF-KO & Increased CFU & Delayed formation & 23 \\
\hline$M$ tuberculosis & TNFRp55-KO & Increased CFU & Delayed formation, necrosis & 26 \\
\hline$M$ bovis $B C G, M$ tuberculosis & tmTNF-TG & No or slightly increased CFU & None or marginal & 37 \\
\hline$M$ tuberculosis & anti-TNF $m A b$ in chronic phase & Increased CFU & Disorganisation, diffuse infiltration & 28 \\
\hline$M$ bovis BCG & anti-TNF mAb & Increased CFU & Malformation, breakdown & 27 \\
\hline$M$ tuberculosis, $M$ bovis BCG & sTNFRp55-TG & Increased CFU & Necrosis & 56 \\
\hline Mavium & TNFRp55-KO & No or marginally increased CFU & Disintegration, disorganised mixed infiltrate & 22,25 \\
\hline M tuberculosis & LT $\alpha-K O$ & Increased CFU & Delayed formation, structural defects & 35 \\
\hline$M$ tuberculosis & LT $\beta R-K O, L T \beta-K O$ & Increased CFU & $\begin{array}{l}\text { Delayed formation, delayed macrophage } \\
\text { activation }\end{array}$ & 36 \\
\hline$M$ bovis BCG & LT $\beta R$-lgGFc & Increased CFU & Marginal & 57 \\
\hline$M$ bovis BCG & TNF-LT $\alpha-K O$ & Increased CFU & Diffuse infiltrations & 58 \\
\hline
\end{tabular}

LT, lymphotoxin; tmTNF, transmembrane TNF; sTNF, soluble TNF; KO, knockout; TG, transgenic; lgGFc, fusion protein; CFU colony forming units. 


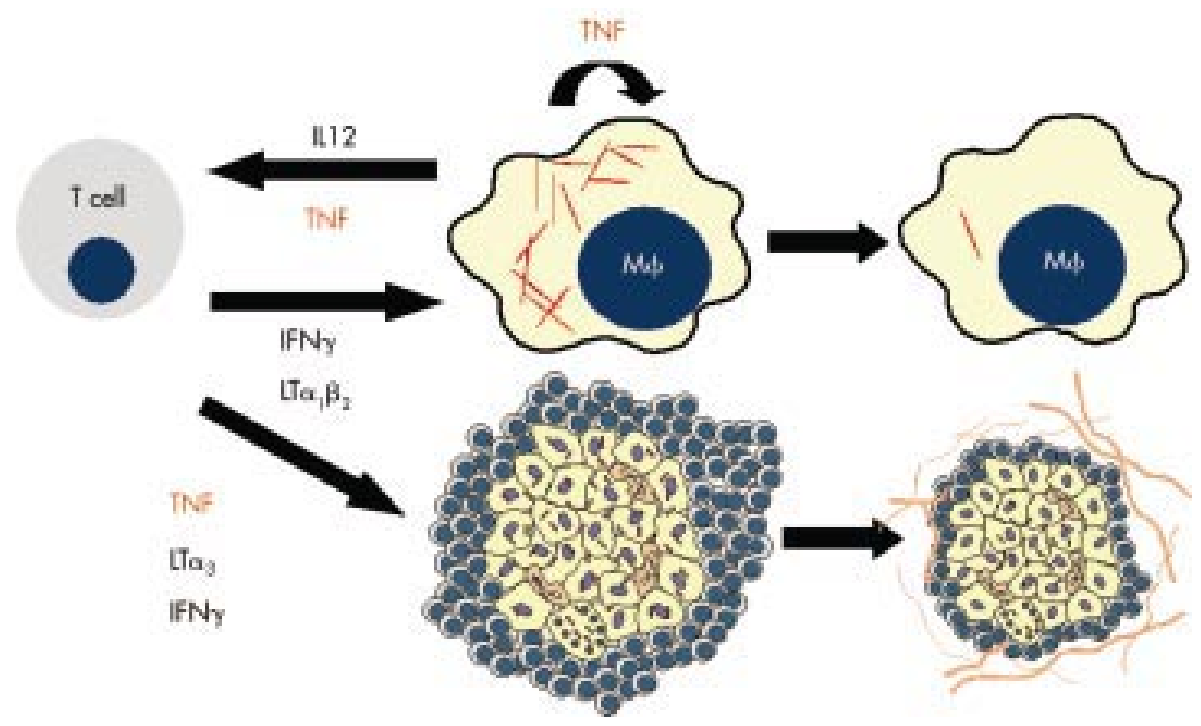

Figure 1 TNF is involved at multiple steps in antibacterial and inflammatory responses to $M$ tuberculosis infection. It is a macrophage activating cytokine and is necessary for the sustained recruitment of inflammatory cells into granulomatous lesions. It is produced by macrophages and $T$ cells, and it strongly synergises with interferon $\gamma$ in containing tuberculous infection by inducing bacterial killing and granuloma development.

TB immunity. For example, TNF increases the phagocytic ability of macrophages and enhances the killing of mycobacteria, particularly in concert with interferon $\gamma \cdot{ }^{18}$ TNF may also deprive mycobacteria of their intracellular sanctuary by inducing apoptosis of permissive macrophages. ${ }^{19}{ }^{20}$ On the other hand, TNF, by virtue of stimulating chemokine production (such as CCL-2, -3, -4, -5, -8) as well as the expression of endothelial cell adhesion molecules (such as CD54), is crucial in inflammatory cell recruitment, leading to the focused accumulation of mononuclear cells. ${ }^{21}$ Thus, in TNF or TNFRp55 deficient mice, granuloma formation is significantly delayed. ${ }^{22}{ }^{23}$ Even incipient granulomas cannot be maintained in the absence of TNF signalling and rapidly disintegrate, causing the death of mycobacteria infected mice. ${ }^{24}$ In this situation TNF presumably regulates the inflammatory response by maintaining the viability of activated macrophages at the site of infection. In addition, TNFRp55 signalling is required for modulation of the $\mathrm{T}$ cell response because in its absence hyperinflammatory $\mathrm{T}$ cell mediated tissue destruction becomes evident. ${ }^{25}$ Because both antibacterially active mechanisms and demarcation of the infectious focus are seriously impaired in the absence of TNF signalling, lesions present as disorganised, diffuse, necrotising infiltrations of mixed cellularity in TNF and TNFR deficient mice ${ }^{26}$ (fig 2).

Granulomatous inflammation is a highly dynamic process, and continuous recruitment of inflammatory cells into the lesion is necessary to maintain antibacterial vigilance. Therefore, even during the chronic phase of infection, when compact granulomas have already been established to wall off the infectious focus, wild-type mice given antibodies effectively neutralising TNF can no longer contain mycobacterial growth within the lesions, and granuloma breakdown is followed by dissemination of mycobacteria. ${ }^{27} 28$

Lymphotoxin (LT) $\alpha$, LT $\beta$, and the recently identified LIGHT (homologous to lymphotoxins, exhibits inducible expression, and competes with HSV glycoprotein D for herpesvirus entry mediator (HVEM), a receptor expressed by T lymphocytes) are also members of the core group of cytokines clustered within the growing TNF superfamily. ${ }^{29-32} \mathrm{LT} \alpha_{3}$ engages the TNFRp55, TNFRp75, and HVEM as homotrimer. ${ }^{29-33}$ In combination with the membrane bound LT $\beta$, LT $\alpha$ binds as the $\mathrm{LT} \alpha_{1} \beta_{2}$ heterotrimer to the LT $\beta R .^{34}$

In experimental $M$ tuberculosis infection, $\mathrm{LT} \alpha_{3}$ has a role similar to that of TNF, as in the absence of $\mathrm{LT} \alpha$, granulomas are not efficiently formed and $\mathrm{T}$ cells do not appropriately enter into the lesions, resulting in premature death of infected mice. ${ }^{35}$ Signalling through the LT $\beta$ R, on the other hand, is necessary for full activation of antibacterial defence mechanisms, and macrophages in LT $\beta \mathrm{R}-\mathrm{KO}$ mice show a gross delay in inducible nitric oxide expression and rapidly succumb to infection. ${ }^{36}$ LIGHT-KO mice proved to be equally resistant to $M$ tuberculosis infection as wild-type mice. ${ }^{36}$

In summary, signalling of TNF and LT $\alpha_{3}$ through the TNF receptors and signalling of $L T \alpha_{1} \beta_{2}$ heterotrimers through the LT $\beta R$ are all essential and non-redundant prerequisites for TB immunity. Importantly, however, in the absence of soluble TNF and $\mathrm{LT}_{3}$ (that is, in genetically manipulated mice expressing only a transmembrane form of TNF) there was only a marginal increase in mycobacterial load and a slight delay in granuloma formation. ${ }^{37}$ This particular result shows that there is significant flexibility in compensating defects within the group of TNF/LT ligands as long as the signalling pathways through the respective receptors are not entirely obliterated.

\section{TNF TARGETING BIOLOGICAL AGENTS: MODE OF ACTION, PHARMACODYNAMICS, AND RISK ASSESSMENT FOR TB}

From the mouse studies described above it is apparent that complete neutralisation of TNF must be avoided because TNF activity is required not only to recruit inflammatory cells but also to regulate antibacterial mechanisms. To avoid serious infectious complications, TNF targeting biological agents should therefore ideally provide significant, but still only partial, inhibition of TNF activity. This may be achieved either by cutting off only peak concentrations of TNF at the site of inflammation, or by interfering with TNF signalling in an intermittent fashion, allowing partial recuperation of some beneficial effects induced by TNF. This strategy of preventing a relapse of tuberculous disease in a patient with rheumatoid arthritis treated with TNF targeting biological agents might create an opportunity in which the inflammation score is decreased to a level that significantly reduces the activity of rheumatoid disease, but is still high enough to ensure turnover of effector cells to granulomatous TB lesions (fig 3).

Two of the currently most widely used TNF targeting biological agents, infliximab and etanercept, differ considerably in their mode of action. Infliximab is a chimeric $(75 \%$ human, $25 \%$ murine) monoclonal antibody with a high binding affinity for both monomeric and trimeric TNF. ${ }^{38}$ It forms very stable complexes with both soluble and transmembrane TNF and scarcely releases soluble or transmembrane TNF once bound to them. ${ }^{38}$ Infliximab does not bind to LT $_{3}$ (fig 4). It can cross link transmembrane TNF, which may result in 

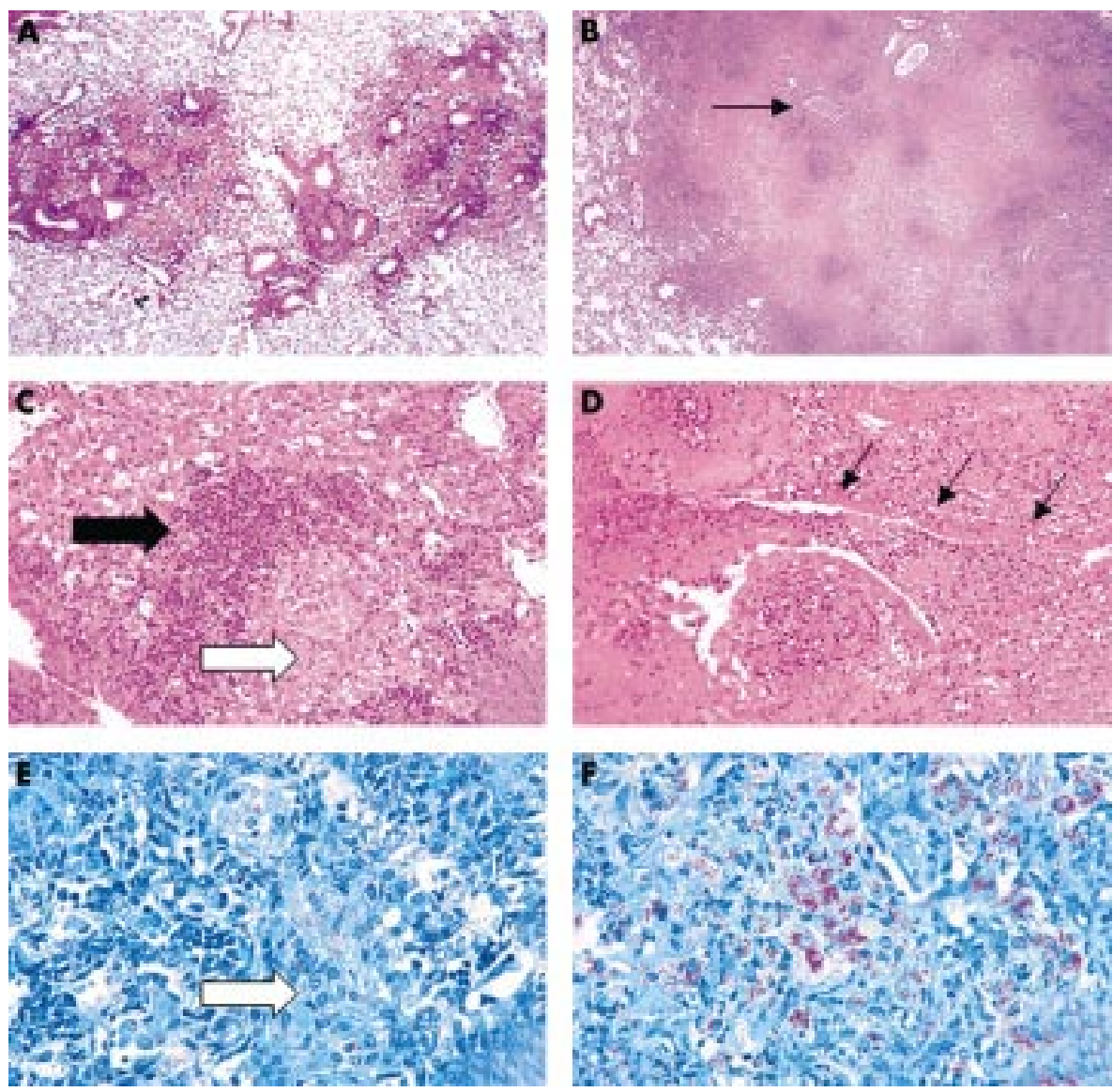

Figure 2 Granulomatous lesions in the lungs of mice aerogenically infected with $M$ tuberculosis. Wild-type (A, C, E) and TNFRp55-knockout (KO) $(B, D, F)$ mice were infected with 100 colony forming units $M$ tuberculosis $H 37 R v$ by aerosol. Mice were killed on day 35 after infection. Haematoxylin and eosin $(A, B \times 12 ; C, D \times 32)$ and Ziehl-Neelsen $(E, F \times 64)$ staining was performed on paraffin embedded lung sections. Note the necrotising lesion with mixed cellular infiltrate and increased numbers of acid fast rods in B, D, and F. Small black arrows in B and D show the rupture of granulomatous lesion into adjacent bronchus in TNFRp55-KO mice. The black arrow in C shows the lymphocytic cuff and the white arrows in $\mathrm{C}$ and $\mathrm{E}$, epithelioid macrophages.

monocyte apoptosis through a caspase dependent, but otherwise little defined mechanism ${ }^{39}$; infliximab bound to transmembrane TNF may also result in complement mediated lysis of cells. ${ }^{40}$ Drug induced monocytopenia has indeed been reported and may contribute to defects in granuloma maintenance in patients harbouring mycobacteria. Moreover, lysis of
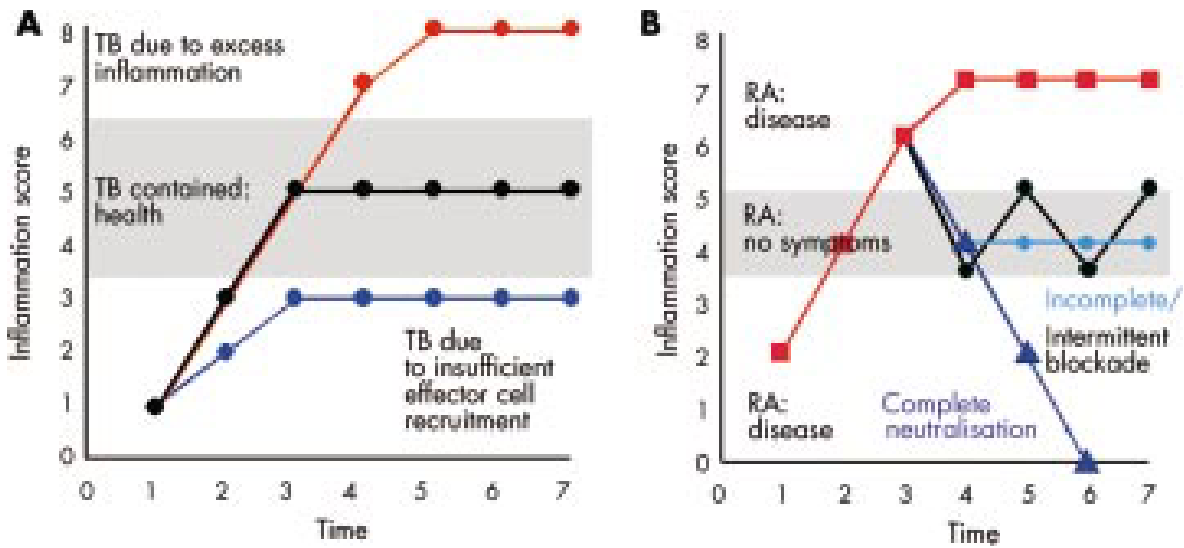

Figure 3 Hypothetical modulation of TNF activity to levels compatible with both containment of TB lesions and alleviation of arthritic symptoms. (A) Inflammation during TB: a high degree of T cell mediated inflammation leads to necrotising granulomas and tissue damage - that is, clinical tuberculosis, over time (red line). A lower degree of inflammatory responses is associated with effective containment of mycobacteria and little tissue destruction (black line, grey area). If there is insufficient recruitment of inflammatory cells to restrict mycobacterial replication within granulomatous lesions, clinical disease again becomes manifest (blue line). (B) Inflammation in rheumatoid arthritis: a high degree of inflammation in rheumatoid arthritis is associated with clinical disease activity (red line). TNF targeting biological agents may completely neutralise TNF activity, resulting in a very low inflammatory score (dark blue line). Less efficient neutralisation (light blue line) or intermittent blockade of TNF (black line) may be sufficient to reduce disease activity to the point at which symptoms of rheumatoid arthritis are alleviated. At the same time, in a patient with latent TB, this strategy may provide a brief opportunity (area shaded in grey) in which TNF levels are high enough to sustain the integrity of granulomas but low enough to reduce arthritis activity. 

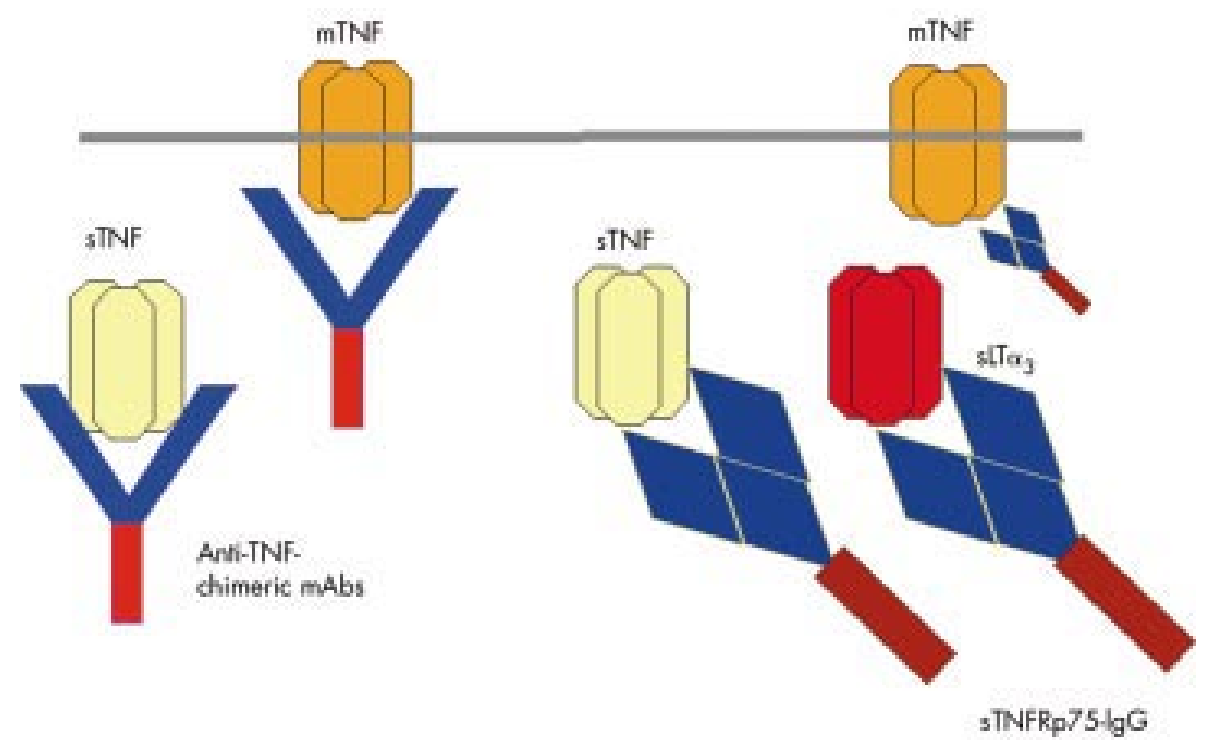

Figure 4 Mode of action of infliximab and etanercept. Chimeric monoclonal antibodies to TNF (infliximab) form stable complexes with both soluble TNF (sTNF) and membrane bound TNF (mTNF), but do not bind to soluble $\mathrm{LT} \alpha_{3}\left(\mathrm{sLT} \alpha_{3}\right)$. TNFRp75-lgG fusion proteins (etanercept) bind to sLT $\alpha_{3}$ and sTNF but have a very low affinity for mTNF.
$M$ tuberculosis infected macrophages may conceivably be involved in dissemination of mycobacteria from the original site of the lesion, resulting in a relatively high frequency of extrapulmonary disease in treated patients.

Etanercept is a dimeric fusion protein comprising the extracellular ligand portion of the human TNFR2 and the FC moiety of human IgGl. Etanercept effectively neutralises soluble TNF and $\mathrm{LT}_{3}$ (fig 4). In vitro, etanercept binds about four times less efficiently to transmembrane TNF than infliximab and is therefore significantly less potent in blocking transmembrane TNF induced effects. ${ }^{38}$ Owing to its relatively fast dissociation rate (compared with infliximab), etanercept sheds about $50 \%$ of soluble TNF and $90 \%$ of transmembrane TNF only 10 minutes after binding. ${ }^{38}$ Etanercept may therefore be described as a "sink" that rapidly traps TNF/LT $\alpha_{3}$ at sites where these mediators are abundant, and rapidly sheds TNF/ $\mathrm{LT} \alpha_{3}$ wherever their surrounding concentration is low.

The pharmacokinetics of both reagents differ considerably. Infliximab has a half life of about nine days, ${ }^{41}$ and is therefore currently given as an intravenous infusion on days 1 and 15 of treatment, followed by maintenance infusions every 6-8 weeks. Etanercept has a half life of about 3.5 days, and is given twice weekly as a subcutaneous injection. ${ }^{41}$ Thus, infliximab treatment probably results in a sustained and complete neutralisation of TNF activity, whereas etanercept may only cut off the peaks of TNF concentration.

From these data, it is difficult to predict a priori which biological agent would have more infectious complications as side effects. The conceivably detrimental effect of neutralising both soluble TNF and $\mathrm{LT}_{3}$ (by etanercept) may be outweighed by a lower overall affinity and shorter half life. Blocking both soluble and membrane TNF very effectively over longer periods of time (by infliximab) is likely to increase the risk of intracellular infections, but may be associated with a better clinical response in certain syndromes such as Crohn's disease. ${ }^{42}$

In view of the experimental studies recording the pivotal role of TNF in $M$ tuberculosis infection, it is not surprising that pharmacological interventions in human patients which neutralise TNF activity have reactivated latent TB or, possibly, exacerbated primary TB. What is perhaps surprising is the fact that treatments with the two currently most widely used biological agents are apparently associated with quite different rates of TB complications. The prevailing impression among clinicians is that $\mathrm{TB}$ complications in patients treated with etanercept are rare compared with those occurring with infliximab. ${ }^{2} 134344$ However, comparisons of the rates of TB reported with infliximab and etanercept treatments must be performed with considerable caution. This is because the patient groups treated have not been stratified according to the variables influencing the overall rate of reactivation, such as age, country of origin, history of travel to high prevalence countries, and occupation (that is, risk of exposure to infected contacts); no trials directly comparing the efficacy of both biological agents have been performed to date. In addition, a detailed survey of $\mathrm{TB}$ reactivation by infliximab has been widely publicised, whereas reports of TB associated with etanercept treatment have mostly been presented in anecdotal form. A comprehensive review on this issue has recently been published. ${ }^{45}$

The trend towards more serious infectious complications in patients treated with infliximab is also supported by recent reports of histoplasmosis associated with these treatments: nine cases of invasive disseminated histoplasmosis were reported in patients receiving infliximab and only one in a patient who had received etanercept. ${ }^{46}{ }^{47}$ Similarly, 14 cases of Listeria monocytogenes infection were reported as a complication of treatment with infliximab as compared with only one case after etanercept treatment. ${ }^{48}$ Although the reasons for this increased risk with infliximab are far from clear, the differences in the mode of action and the pharmacodynamic behaviour of the two biological agents outlined above may provide clues for a tentative explanation. From this reasoning, it is suggested that a reduction in infliximab dose and/or adjustment of infusion intervals should be accompanied by a reduced incidence of infectious complications.

\section{LESSONS FROM COMPLICATIONS: THE SEARCH FOR NEW TARGETS DOWNSTREAM FROM TNF}

The currently available information on infectious complications incurred by TNF targeting biological agents suggests that taking advantage of distinct pharmacodynamic properties and carefully adjusting dosage and treatment intervals may help to reduce severe complications such as reactivation of TB. Management of the patients eligible for TNF targeting therapies by testing for prior exposure to $\mathrm{TB}$ and prophylactic treatment has been reviewed elsewhere. ${ }^{45}{ }^{49}$

Obviously, if only the proinflammatory events induced by TNF could be selectively blocked, treatment of chronic inflammatory disorders would be more tailored to the actual disease and infectious complications would be less common. Possibly, therefore, a more detailed elucidation of the downstream effector mechanisms of TNF will yield new targets whose 
involvement is restricted to inflammation and tissue destruction and which are distinct from antibacterial effector mechanisms. Adhesion molecules such as CD54 (intercellular adhesion molecule-1 (ICAM-1)) are promising targets. ${ }^{50}{ }^{51}$ In this respect, mice defective in exon 3 of CD54 were fully capable of restricting the growth of an $M$ tuberculosis challenge inoculum, although granulomatous inflammation was significantly reduced. ${ }^{52}$ Chemokines are potentially useful targets because their function is partially redundant, so that it is unlikely that any one blocking therapy will result in $100 \%$ inhibition of inflammation. ${ }^{53}$ This may afford an opportunity in which the inflammatory response is titred to levels compatible with continuous cell recruitment into sites of infection to initiate the antibacterial response, but too low to sustain disease progression in inflammatory processes such as rheumatoid arthritis. Finally, insight into the mechanism governing bone resorption and repair has defined other members of the TNF superfamily such as RANK (receptor activator of NF- $\mathrm{KB}$ ) and RANKL (RANK ligand), ${ }^{545}$ whose manipulation is closer to the rheumatic disease process than the still relatively non-specific inhibition of an inflammatory response by therapeutic agents targeting TNF activity.

\section{ACKNOWLEDGEMENTS}

Work in my laboratory is supported by grants from the Deutsche Forschungsgemeinschaft (SFB 367-C9, SFB 415-C7, SFB 470-C9, GRK288-C3, GRK288-A3), from the BMBF (Ministry of Education and Research), the BMG (Ministry of Health), and the Research Focus on Host Defence against Infection at the University of Lubeck.

\section{Author's affiliation}

S Ehlers, Molecular Infection Biology, Research Centre Borstel, D-23845 Borstel, Germany

Correspondence to: Professor S Ehlers, Division of Molecular Infection Biology, Research Centre Borstel, Parkallee 22, D-23845 Borstel, Germany; sehlers@fz-borstel.de

\section{REFERENCES}

1 Sandborn WJ, Hanaver SB. Infliximab in the treatment of Crohn's disease: a user's guide for clinicians. Am J Gastroenterol 2002;97:2962-72.

2 Keating GM, Perry CM. Infliximab: an updated review of its use in Crohn's disease and rheumatoid arthritis. BioDrugs 2002;16:111-48.

3 Fleischmann R. Safety and efficacy of disease-modifying anti-rheumatic agents. Exp Opin Drug Safety (in press).

4 Chaudhari U, Romano P, Mulcahy LD, Dooley LT, Baker DG, Gottlieb $A B$. Efficacy and safety of infliximab monotherapy for plaque-type psoriasis: a randomised trial. Lancet 2001;357:1842-7.

5 Braun J, Brandt J, Listing J, Zink A, Alten R, Golder W, et al. Treatment of active ankylosing spondylitis with infliximab: a randomised controlled multicentre trial. Lancet 2002;359:1 187-93.

6 El Shabrawi Y, Hermann J. Anti-tumor necrosis factor-alpha therapy with infliximab as an alternative to corticosteroids in the treatment of human leukocyte antigen B27-associated acute anterior uveitis. Ophthalmology 2002; 109:2342-6

7 Reimold AM. New indications for treatment of chronic inflammation by TNF-alpha blockade. Am J Med Sci 2003:325:75-92.

8 Shanahan JC, St Clair W. Tumor necrosis factor-alpha blockade: a novel therapy for rheumatic disease. Clin Immunol 2002;103:231-42.

9 Lipsky PE, van der Heijde DM, St Clair EW, Furst DE, Breedveld FC, Kalden JR, et al. Infliximab and methotrexate in the treatment of rheumatoid arthritis. Anti-Tumor Necrosis Factor Trial in Rheumatoid Arthritis with Concomitant Therapy Study Group. N Engl J Med 2000;343:1594-602.

10 Criscione LG, St Clair EW. Tumor necrosis factor-alpha antagonists for the treatment of rheumatic diseases. Curr Opin Rheumatol 2002; 14:204-11.

11 Richard-Miceli C, Dougados M. Tumour necrosis factor-alpha blockers in rheumatoid arthritis: review of the clinical experience. BioDrugs 2001;15:251-9.

12 Weisman $\mathrm{MH}$. What are the risks of biologic therapy in rheumatoid arthritis? An update on safety. J Rheumatol Suppl 2002;65:33-8.

13 Keane J, Gershon S, Wise RP, Mirabile-Levens E, Kasznica J, Schwieterman WD, et al. Tuberculosis associated with infliximab, a tumor necrosis factor alpha-neutralizing agent. N Engl J Med 2001;345:1098-104.

14 Old LJ. Tumor necrosis factor. Sci Am 1988;258:59-75.
15 Papadakis KA Targan SR. Tumor necrosis factor: biology and therapeutic inhibitors. Gastroenterology 2000; 1 19:1 148-57.

16 Sedgwick JD, Riminton DS, Cyster JG, Korner H. Tumor necrosis factor: a master-regulator of leukocyte movement. Immunol Today 2000;21:110-13.

17 Wajant H, Pfizenmaier K, Scheurich P. Tumor necrosis factor signaling. Cell Death Differ 2003;10:45-65.

18 Bekker LG, Freeman S, Murray PJ, Ryffel B, Kaplan G. TNF-alpha controls intracellular mycobacterial growth by both inducible nitric oxide synthase-dependent and inducible nitric oxide synthase-independent pathways. J Immunol 2001;166:6728-34.

19 Keane J, Remold HG, Kornfeld H. Virulent Mycobacterium tuberculosis strains evade apoptosis of infected alveolar macrophages. J Immunol $2000 ; 164: 2016-20$

20 Fratazzi C, Arbeit RD, Carini C, Balcewicz-Sablinska MK, Keane J, Kornfeld $\mathrm{H}$, et al. Macrophage apoptosis in mycobacterial infections. J Leukoc Biol 1999:66:763-4.

21 Roach DR, Bean AG, Demangel C, France MP, Briscoe H, Britton WJ. TNF regulates chemokine induction essential for cell recruitment, granuloma formation, and clearance of mycobacterial infection. J Immunol 2002; 168:4620-7.

22 Ehlers S, Benini J, Kutsch S, Endres R, Rietschel ET, Pfeffer K. Fatal granuloma necrosis without exacerbated mycobacterial growth in fumor necrosis factor receptor p55 gene-deficient mice intravenously infected with Mycobacterium avium. Infect Immun 1999;67:3571-9.

23 Bean AG, Roach DR, Briscoe H, France MP, Korner H, Sedgwick JD, et al. Structural deficiencies in granuloma formation in TNF gene-targeted mice underlie the heightened susceptibility to aerosol Mycobacterium tuberculosis infection, which is not compensated for by lymphotoxin. J Immunol 1999; 162:3504-11

24 Benini J, Ehlers EM, Ehlers S. Different types of pulmonary granuloma necrosis in immunocompetent vs. TNFRp55-gene-deficient mice aerogenically infected with highly virulent Mycobacterium avium. J Pathol 1999; 189:127-37.

25 Ehlers S, Kutsch S, Ehlers EM, Benini J, Pfeffer K. Lethal granuloma disintegration in mycobacteria-infected TNFRp55-/- mice is dependent on T cells and IL-12. J Immunol 2000; 165:483-92.

26 Flynn JL, Goldstein MM, Chan J, Triebold KJ, Pfeffer K, Lowenstein CJ, et al. Tumor necrosis factor-alpha is required in the protective immune response against Mycobacterium tuberculosis in mice. Immunity 1995;2:561-72.

27 Kindler V, Sappino AP, Grau GE, Piguet PF, Vassalli P. The inducing role of tumor necrosis factor in the development of bactericidal granulomas during BCG infection. Cell 1989:56:731-40.

28 Mohan VP, Scanga CA, Yu K, Scott HM, Tanaka KE, Tsang E, et al. Effects of tumor necrosis factor alpha on host immune response in chronic persistent tuberculosis: possible role for limiting pathology. Infect Immun 2001;69: 1847-55.

29 Ware CF, VanArsdale TL, Crowe PD, Browning JL. The ligands and receptors of the lymphotoxin system. Curr Top Microbiol Immunol 1995; 198:175-218.

30 Sacca R, Cuff CA, Ruddle NH. Mediators of inflammation. Curr Opin Immunol 1997;9:851-7.

31 Smith CA, Farrah T, Goodwin RG. The TNF receptor superfamily of cellular and viral proteins: activation, costimulation, and death. Cell 1994;76:959-62

32 Locksley RM, Killeen N, Lenardo M. The TNF and TNF receptor superfamilies: integrating mammalian biology. Cell 2001;104:487-501.

33 Mauri DN, Ebner R, Montgomery RI, Kochel KD, Cheung TC, Yu GL, et al. LIGHT, a new member of the TNF superfamily, and lymphotoxin alpha are ligands for herpesvirus entry mediator. Immunity 1998;8:21-30.

34 Futterer A, Mink K, Luz A, Kosco-Vilbois MH, Pfeffer K. The lymphotoxin beta receptor controls organogenesis and affinity maturation in peripheral lymphoid tissues. Immunity 1998;9:59-70.

35 Roach DR, Briscoe H, Saunders B, France MP, Riminton S, Britton WJ. Secreted lymphotoxin-alpha is essential for the control of an intracellular bacterial infection. J Exp Med 2001;193:239-46.

36 Ehlers S, Holscher C, Scheu S, Tertilt C, Hehlgans T, Suwinski J, et al. The lymphotoxin beta receptor is critically involved in controlling infections with the intracellular pathogens Mycobacterium tuberculosis and Listeria monocytogenes. J Immunol 2003;170:5210-18.

37 Olleros ML, Guler R, Corazza N, Vesin D, Eugster HP, Marchal G, et al. Transmembrane TNF induces an efficient cell-mediated immunity and resistance to Mycobacterium bovis bacillus Calmette-Guerin infection in the absence of secreted TNF and lymphotoxin-alpha. J Immunol 2002; 168:3394-401.

38 Scallon B, Cai A, Solowski N, Rosenberg A, Song XY, Shealy D, et al Binding and functional comparisons of two types of tumor necrosis factor antagonists. J Pharmacol Exp Ther 2002;301:418-26.

39 Lugering A, Schmidt M, Lugering N, Pauels HG, Domschke W Kucharzik T. Infliximab induces apoptosis in monocytes from patients with chronic active Crohn's disease by using a caspase-dependent pathway. Gastroenterology 2001;121:1145-57.

40 Scallon BJ, Moore MA, Trinh H, Knight DM, Ghrayeb J. Chimeric anti-TNF-alpha monoclonal antibody $\mathrm{CA} 2$ binds recombinant transmembrane TNF-alpha and activates immune effector functions. Cytokine 1995;7:251-9

41 Mikuls TR, Moreland LW. TNF blockade in the treatment of rheumatoid arthritis: infliximab versus etanercept. Expert Opin Pharmacother $2001 ; 2: 75-84$

42 Sandborn WJ, Hanauer SB, Katz S, Safdi M, Wolf DG, Baerg RD, et al. Etanercept for active Crohn's disease: a randomized, double-blind, placebo-controlled trial. Gastroenterology 2001;121:1088-94. 
43 Fleischmann RM, Baumgartner SW, Tindall EA, Weaver AL, Moreland LW, Schiff MH, et al. Response to etanercept (Enbrel®) in elderly patients with rheumatoid arthritis: a retrospective analysis of clinical trial results. J Rheumatol 2003;30:691-6.

44 Antoni C, Braun J. Side effects of anti-TNF therapy: current knowledge. Clin Exp Rheumatol 2002;20:S152-7.

45 Gardam MA, Keystone EC, Menzies R, Manners S, Skamene E, Long R, et al. Anti-tumour necrosis factor agents and tuberculosis risk: mechanisms of action and clinical management. Lancet Infect Dis 2003;3: 148-55

46 Lee JH, Slifman NR, Gershon SK, Edwards ET, Schwieterman WD, Siegel JN, et al. Life-threatening histoplasmosis complicating immunotherapy with tumor necrosis factor alpha antagonists infliximab and etanercept. Arthritis Rheum 2002;46:2565-70.

47 Wood KL, Hage CA, Knox KS, Kleiman MB, Sannuti A, Day RB, et al. Histoplasmosis after treatment with anti-tumor necrosis factor-alpha therapy. Am J Respir Crit Care Med 2003; 167:1279-82.

48 Slifman NR, Gershon SK, Lee JH, Edwards ET, Braun MM. Listeria monocytogenes infection as a complication of treatment with tumor necrosis factor alpha-neutralizing agents. Arthritis Rheum 2003:48:319-24

49 Furst DE, Cush J, Kaufmann S, Siegel J, Kurth R. Preliminary guidelines for diagnosing and treating tuberculosis in patients with rheumatoid arthritis in immunosuppressive trials or being treated with biological agents. Ann Rheum Dis 2002;61 (suppl II):ii62-3.
50 Haraoui B Strand V, Keystone E. Biologic agents in the treatment of rheumatoid arthritis. Curr Pharm Biotechnol 2000;1:217-33.

51 van Assche G, Rutgeerts P. Antiadhesion molecule therapy in inflammatory bowel disease. Inflamm Bowel Dis 2002;8:291-300.

52 Johnson CM, Cooper AM, Frank AA, Orme IM. Adequate expression of protective immunity in the absence of granuloma formation in Mycobacterium tuberculosis-infected mice with a disruption in the intracellular adhesion molecule 1 gene. Infect Immun 1998;66:1666-70.

53 Godessart N, Kunkel SL. Chemokines in autoimmune disease. Curr Opin Immunol 2001;13:670-5.

54 Jones DH, Kong YY, Penninger JM. Role of RANKL and RANK in bone loss and arthritis. Ann Rheum Dis 2002;61 (suppl II:ii32-9.

55 Romas E, Gillespie MT, Martin TJ. Involvement of receptor activator of NFkappaB ligand and tumor necrosis factor-alpha in bone destruction in rheumatoid arthritis. Bone 2002;30:340-6.

56 Garcia I, Miyazaki Y, Marchal G, Lesslauer W, Vassalli P. High sensitivity of transgenic mice expressing soluble TNFR 1 fusion protein to mycobacterial infections: synergistic action of TNF and IFN-gamma in the differentiation of protective granulomas. Eur J Immunol 1997;27:3182-90.

57 Lucas R, Tacchini-Cottier F, Guler R, Vesin D, Jemelin S, Olleros ML, et al. A role for lymphotoxin beta receptor in host defense against Mycobacterium bovis BCG infection. Eur J Immunol 1999;29:4002-10.

58 Jacobs M, Brown N, Allie N, Ryffel B. Fatal Mycobacterium bovis BCG infection in TNF-LT-alpha-deficient mice. Clin Immunol 2000;94:192-9. 